\title{
EFFECT OF ELECTROLYTE ON THE ELECTROCHEMICAL AND STRUCTURAL PROPERTIES OF THE TIO2 LAYER ELABORATED BY ANODIZATION
}

\author{
${ }^{1 *}, 2$ Djamila ATMANI, ${ }^{2}$ Nadia SAOULA, ${ }^{3}$ Abderrezak ABDI, ${ }^{3}$ Hadjer BELATTAR, \\ ${ }^{1}$ Mohamed AZZAZ \\ ${ }^{1 *}$ Laboratory of Material Science and Engineering, University of Science and Technology Houari \\ Boumediene, Bab Ezzouar, Algeria, datmani@cdta.dz \\ ${ }^{2}$ Division of lonized environments and Lasers, The Center for Development of Advanced \\ Technologies (CDTA), Alger, Algeria \\ ${ }^{3}$ Laboratory of Electrochemistry and Corrosion, Polytechnic Military School, \\ Bordj El Bahri, Alger, Algeria
}

https://doi.org/10.37904/metal.2019.722

\begin{abstract}
The electrochemical anodization of titanium has received a lot of attention in recent years, especially for its application for biomedical purposes, offering a biocompatible titanium oxide with architecture of a large energy surface, and highly controllable nanoscale characteristics.

In this work, TiO2 layers were synthesized on a well-polished titanium surface, by the anodizing technique, under a voltage of $20 \mathrm{~V}$, for 15,30 and 45 minutes respectively, using as specific electrolyte: $1 \mathrm{M} \mathrm{CH} 3 \mathrm{COOH}$ /1M Na2SO4/0.5 Wt\% NaF.

Interfacial integrity and variation of elemental composition along the interface were studied by scanning electron microscopy (SEM), equipped with an energy dispersive X-ray analyzer (EDX). Electrochemical behaviour was studied both by measuring the evolution of open circuit potential (OCP), by electrochemical impedance spectroscopy (EIS), and by linear polarization (LP) in Hank's solution as a physiological environment. The nature of the crystalline phase formed during the annealing treatment was demonstrated by Raman spectroscopy and X-ray diffraction (XRD) technique. SEM characterization reveals uniform and vertically aligned networks of $\mathrm{TiO}_{2}$ nanotubes $\left(\mathrm{TiO}_{2}-\mathrm{NT}\right)$ on titanium substrates, without a significant effect of anodization time on the diameter of the nanotubes. On the other hand, the EIS measurements show a significant improvement in corrosion behaviour.
\end{abstract}

Keywords: Anodic oxidation, EIS, Ti6A4V, DRX, biocompatibility

\section{INTRODUCTION}

In recent years, titanium and its alloys have been considered ideal candidates for applications in the biomedical field as a hard tissue replacement implant or in cardiovascular applications. This enthusiasm for these materials is due to their low modulus of elasticity, their biocompatibility and their good resistance to corrosion and fatigue [1]. On the surface of titanium and its alloys, a thin oxide layer develops naturally, which is favorable to osteointegration. However, the stability of this layer, which is highly dependent on thickness and structure, does not meet all clinical requirements in highly aggressive biological environments. Consequently, surface modifications are necessary to improve its stability. Various methods have been used to improve the interfacial properties and clinical life time of titanium implants: sol-gel [2], electrophoretic [3], hydrothermal [4-5] or anodization [6-7]. The latter is one of the most widely used techniques to produce Nano porous oxide layers; formed of nanotubes or nanowires and whose size and shape can be adjusted [8]. In addition to its simplicity and feasibility, this technique offers a wide range of applications for these materials: as photocatalyst, gas sensor, optical coating, bone implant for biocompatibility, in the photovoltaic field [9-10]. In this study, the 
development of titanium oxide nanotubes by anodizing in acetic acid medium was investigated. We examined the influence of anodizing time and the presence of small amounts of $\mathrm{NaF}$ and Urea, used as additives.

\section{EXPERIMENTAL SECTION}

\subsection{Preparation of Samples}

Commercially pure titanium alloy grade 5 (Ti6Al4V) sheet, obtained from France (Titanium Services France SAS), was used for anodizing experiments (wt\% chemical composition: $0.05 \mathrm{~N}, 0.08 \mathrm{C}, 0.0125 \mathrm{H}, 0.25 \mathrm{Fe}$, $0.13 \mathrm{O}, 6 \mathrm{Al}, 4 \mathrm{~V}$, and Ti balance). Test samples, $40 \times 15 \times 1 \mathrm{~mm}$ cut from the sheet were ground different grades of silicon carbide papers. These samples were ultrasonically cleaned using acetone and dried. The Ti plates were then cleaned with distilled water and etched in a mixture of HNO3: HF: $\mathrm{H} 2 \mathrm{O}$ (5:2:3) at room temperature, and finally rinsed and dried in air.

\subsection{TiO2 Oxide Layers Elaboration}

The anodization process was carried out using a two-electrode electrochemical cell, with Ti6Al4V alloy as anode and a copper sheet as cathode, under a direct-current (DC) under a constant direct current (DC) bias of $20 \mathrm{~V}$ at different times ranging from 15, 30 and $45 \mathrm{~min}$. The distance between the two electrodes was kept at $3 \mathrm{~cm}$, in all experiments. The used electrolyte bath was a $100 \mathrm{ml}$ solution of 1 (M) $\mathrm{Na}_{2} \mathrm{SO}_{4}$ and $\mathrm{CH}_{3} \mathrm{COOH}$ (1M) which contains $\mathrm{NaF}(0.5 \mathrm{wt} \%)$. The $\mathrm{pH}(\sim 4)$ was adjusted with $0.1 \mathrm{~m} \mathrm{H}_{2} \mathrm{SO}_{4}$. All experiments were performed under vigorous magnetic stirring at room temperature $\left(20-25^{\circ} \mathrm{C}\right)$. The anodized samples were rinsed in deionized water, dried, and then annealed at $500{ }^{\circ} \mathrm{C}$ for $2 \mathrm{~h}$ in air. At least, the samples were ultrasonically cleaned using acetone and ethanol for $15 \mathrm{~min}$ and dried. The samples were characterized by scanning electron microscopy (SEM), X-Ray diffraction (XRD) and Raman spectroscopy. SEM (JEOLJEOL 6300), equipped with an energy dispersive spectrometer (EDS) for the chemical analysis. The obtained TiO2 nanostructures were determined by X-ray diffraction (XRD) via Brucker Axe D8 Advance diffractometer (Cu Ka radiation, $\lambda=1.5406{ }^{\circ} \mathrm{A}$, over the $2 \theta$ range $\left(20-80^{\circ}\right)$, with a scanning rate of $1^{\circ} \mathrm{min}^{-1}$.

\subsection{Electrochemical Tests}

A conventional three-electrode electrochemical cell system was used. Saturated calomel electrode (SCE) and platinum mesh were used as reference and counter electrodes, respectively. The physiological environment of the human body was simulated with Hank's solution for in vitro corrosion studies [11]. The electrochemical impedance spectroscopy (EIS) studies were conducted in AC-frequency domain using Biologic SP-150 system from $100 \mathrm{kHz}$ to $10 \mathrm{mHz}$, with $5 \mathrm{mV}$ amplitude around the open circuit potential (OCP). The temperature was thermostatically kept at $37^{\circ} \mathrm{C}$, and the $\mathrm{pH}$ was measured to be 7.40 .

\section{CHARACTERIZATION OF $\mathrm{TIO}_{2}$ OXIDE}

\subsection{Morphology characterization}

Anodization is a simple electrolytic technique with reproducible and controllable application to grow different oxides, morphology, ordered nanotubes, nanowires and nanopores. Figure 1 shows the surface morphology of the sample prepared for different times of 15,30 , and $45 \mathrm{~min}$, at constant voltage of $20 \mathrm{~V}$, in acetic acid medium $\left(\mathrm{CH}_{3} \mathrm{COOH}\right)$. In order to convert amorphous oxides into crystalline, all samples were annealed at $500{ }^{\circ} \mathrm{C}$ for 2 hours. According to [12], the oxide layer produced by anodization is mainly in an amorphous form but also contain some crystalline phases, depending on the anodization process parameters [13].

Independently on the process parameters, electrolyte, anodization time, oxide layers constituted of $\mathrm{TiO}_{2}$ were obtained (Figure 1d). Nevertheless, the morphology of oxide layer depended on the anodization conditions. Figures $1(a, b, c)$ shows typical images of the oxide surface: porous structure and nanotubular structure. 

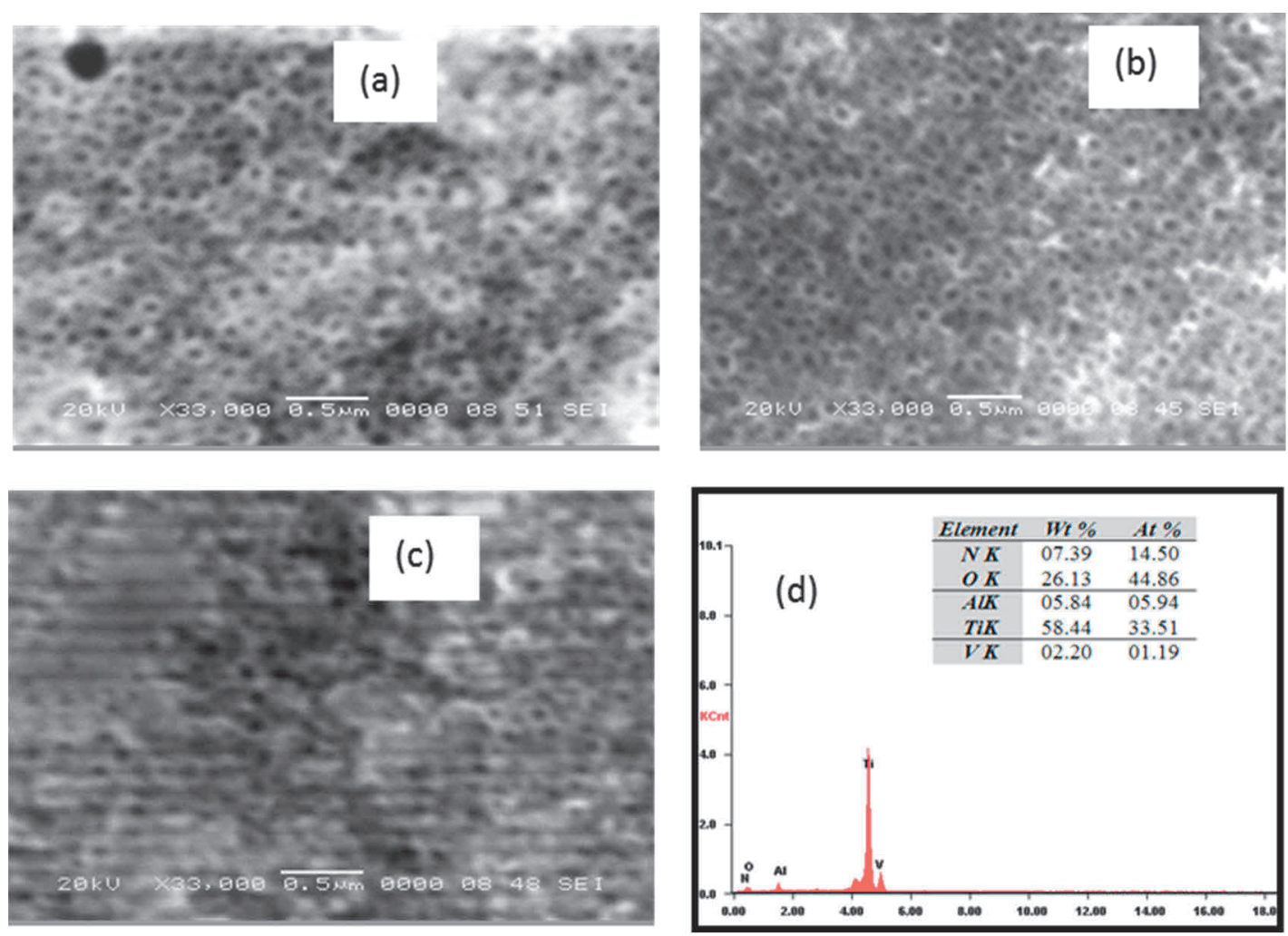

Figure 1 SEM images of oxide layers obtained in acetic acid $1 \mathrm{M}$ and $0.5 \mathrm{wt} \% \mathrm{NaF}$ under following processing conditions: (a) $15 \mathrm{~min}$,( b) $30 \mathrm{~min}$, (c) $45 \mathrm{~min}$, (d) EDS spectrum of oxide layer obtained in $20 \mathrm{~V}$

The $\mathrm{TiO}_{2}$-NT obtained when anodization at 15, 30 min times (Figures $1(\mathbf{a}, \mathbf{b})$ ), formation of nanotubes was observed. Previous study was reported $15 \mathrm{~min}$ as lowest time for the formation of nanotubes in aqueous medium containing fluorure ion F-. Generally, the formation of $\mathrm{TiO}_{2}$ nanotubes is a competition of field enhanced $\mathrm{TiO}^{2}$ grow that $\mathrm{Ti}^{2} \mathrm{TiO}^{2}$ interface and field assisted dissolution of nanotubes at $\mathrm{TiO}^{2} /$ solution interface. The dominancy of either process largely depends on the electrolyte composition and process parameters (times and voltage). A times is an important parameter for growth nanotubes, differences study synthesis a nanotubes a high times. It is well established that the formation and growth of nanotubes in fluoride containing electrolytes depends on two processes i.e., (1) field assisted oxidation of titanium at the metal/oxide inter-face (reactions 1 and 2), (2) field assisted chemical dissolution with in the tube at TiO2 / electrolyte interface by producing water soluble complexes which controls the diameter and wall thickness of nanotubes, according to equations (3) and (4) [13].

The formation and growth of nanotubes depends on the competition between mechanisms [1].

$$
\begin{array}{lll}
\mathrm{Ti} & \rightarrow & \mathrm{Ti}^{4+}+4 \mathrm{e}^{-} \\
\mathrm{Ti}^{4+}+2 \mathrm{H}_{2} \mathrm{O} & \rightarrow & \mathrm{TiO}_{2}+4 \mathrm{H}^{+} \\
\mathrm{Ti}^{4+}+6 \mathrm{~F}^{-} & \rightarrow & {\left[\mathrm{TiF}_{6}\right]^{2-}} \\
\mathrm{TiO}_{2}+6 \mathrm{~F}^{-}+4 \mathrm{H}^{+} \rightarrow & {\left[\mathrm{TiF}_{6}\right]^{2-}+2 \mathrm{H}_{2} \mathrm{O}}
\end{array}
$$

S. Sreekanta [5] reported in their study a formation of nanotubes after $15 \mathrm{~min}$ of anodizing process. For longer anodizing times $(15 \mathrm{~min}<)$, they observed a compact oxide layers. All anodizing samples at $20 \mathrm{~V}$, for all times, reveal a well structured layer, with nanotubes of approximately $80 \mathrm{~nm}$ size diameter. Regonini [8] has successfully synthesized nanotubes in presence fluoride ions; he got a better morphology with $100 \mathrm{~nm}$ pore diameter. 

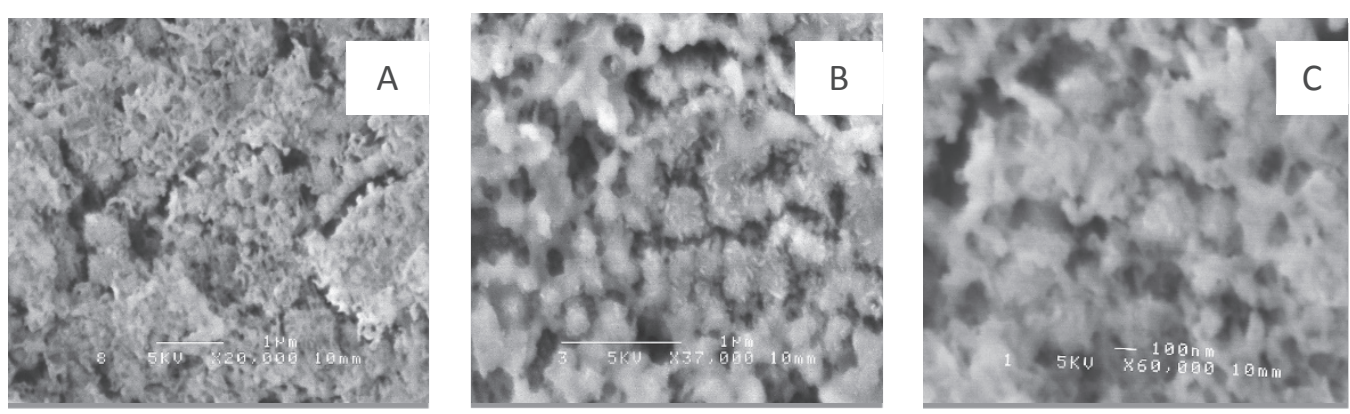

Figure $2 \mathrm{SEM}$ images of oxide layers obtained in $\mathrm{Na}_{2} \mathrm{SO}_{4} 1 \mathrm{M}$ and $0.5 \mathrm{wt} \% \mathrm{NaF}$ under following processing conditions: (a) $15 \mathrm{~min}$, (b) $30 \mathrm{~min}$, (c) $45 \mathrm{~min}$, at $20 \mathrm{~V}$

In order to make comparison with the $\mathrm{NaF} / \mathrm{CH}_{3} \mathrm{COOH}$ based electrolyte, the titanium based specimens were we also anodized a in a $\mathrm{NaF} / \mathrm{Na}_{2} \mathrm{SO}_{4}$ solution specimen at $20 \mathrm{~V}$ [14]. As expected, the structure is strongly disrupted by oxygen bubbles, generated during the formation of NTs, depending on the mechanism, with the presence of oxide aggregates in the form of a compact layer, Figure $\mathbf{2 a}$, and pores showing the beginning of NT formation, Figure $\mathbf{2 b}$ and Figure $\mathbf{2 c}$.

It can be argued that if a higher dissolution rate and a longer anodizing time contribute to the formation of a porous and highly ordered structure in an acid electrolyte, the presence of oxide layer should not be considered in aqueous media, given the conditions are much more aggressively [8]. However, when NTs are formed in an aqueous medium, the anodic structure is highly hydrated.

\subsection{Structural Characterization}

The characterization of the structure was investigated by X-ray diffraction. TiO2 is a polymorphic ceramic material, which could exist, in three well-known structural forms: rutile (tetragonal), anatase (tetragonal), and brookite (orthorhombic).

Annealing was carried at $500{ }^{\circ} \mathrm{C}$ for 2 hour to crystallize the amorphous nanotube arrays formed as a result of anodization. This is confirmed by form the result in XRD patterns Figure 3, showing several dominatnt peaks of anatase phase after annealing. They indicate diffraction peaks at $2 \theta$ at $25.5^{\circ}, 34.7^{\circ}$ and $47.6^{\circ}$ that are identified to be (101), (002) and (004) crystal faces, respectively to Anatase crystalline phase. We detected peaks from the rutile phase of $\mathrm{TiO} 2$, but their intensity is relatively weak.
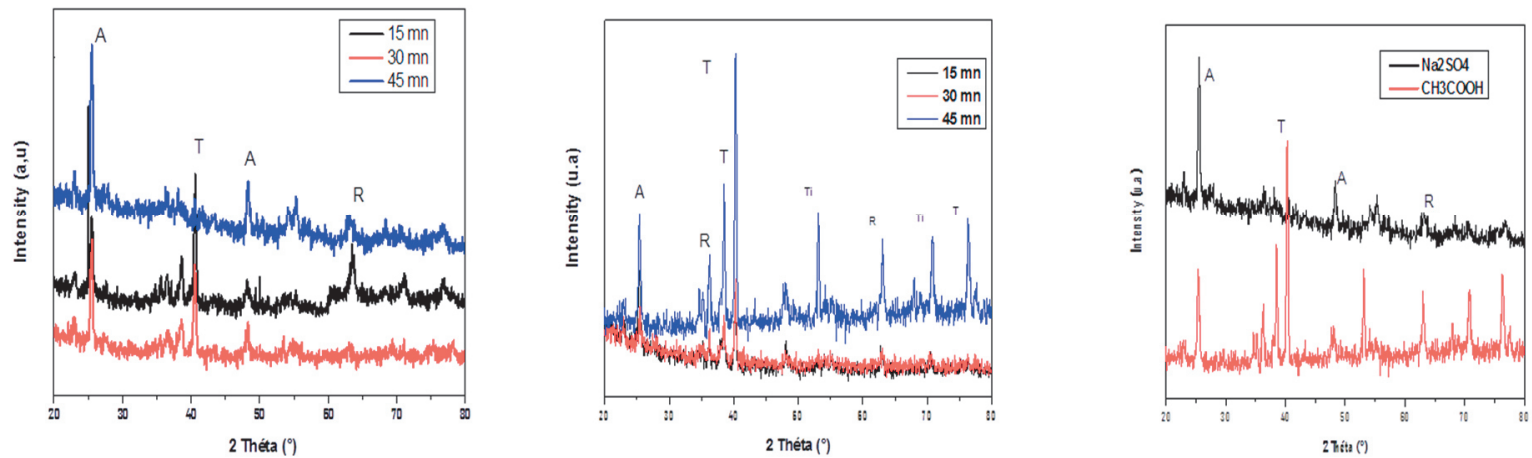

Figure $3 \mathrm{XRD}$ patterns of (a) treated in $\mathrm{Na} 2 \mathrm{SO} 4$, (b) $\mathrm{CH} 3 \mathrm{COOH}$, (c) XRD spectra with various electrolytes [own study]

The DRX analysis reveals no significant influence of the nature of the electrolyte on the elementary composition of the elaborated phases, whereas, intensities of the anatase peaks developed in $\mathrm{Na}_{2} \mathrm{SO}_{4}$ are more intense than those associated to the $\mathrm{CH}_{3} \mathrm{COOH}$ electrolyte. 


\subsection{Electrochemical test}

Figure 4 shows the EIS spectra carried out over the frequency range $\left(10^{-2}-10^{5} \mathrm{~Hz}\right)$, around the OCP in Hanks' Balanced Salt Solution (HBSS). For the titanium sample anodized sample during 15 minutes. For the titanium samples anodized in $\mathrm{CH}_{3} \mathrm{COOH}$ electrolyte, a distorted semicircle appears in the high frequency and a clear sloped straight line in the low frequencies, associated to Warburg diffusion process, with a slope of - 0.51 (very close to the ideal value -0.5 ), and with an independent frequency phase angle of $\sim-\pi / 4$. However, for the samples anodized in $\mathrm{Na}_{2} \mathrm{SO}_{4}$ medium, two distorted semicircles appear in the high and the low frequency domain, respectively.
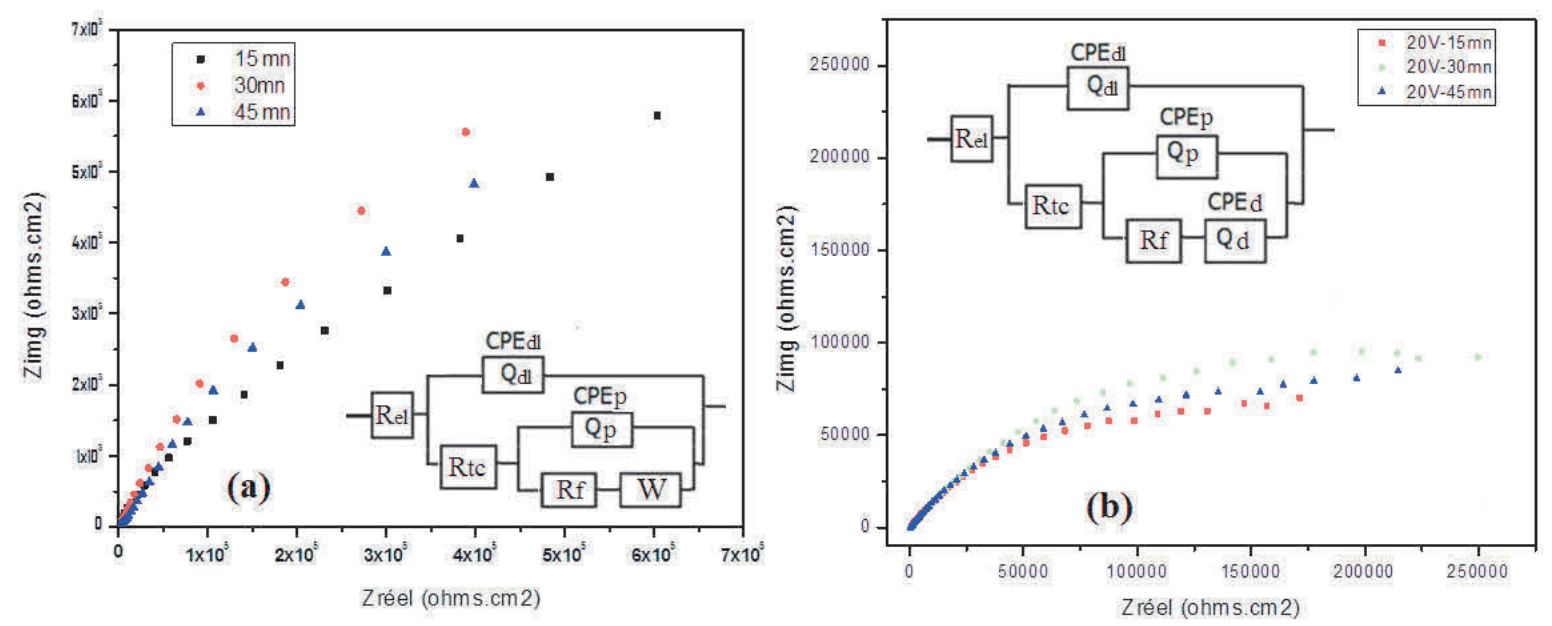

Figure 4 Nyquist diagrams performed in Hank's solution and the associated equivalent circuit models of $\mathrm{TiO}_{2}$-NT samples anodized in (a) $\mathrm{CH}_{3} \mathrm{COOH}$, (b) $\mathrm{Na}_{2} \mathrm{SO}_{4}$ electrolyte for 15,30 and 45 min, at 20 Volts

The related equivalent circuit models (Figure 4, insert) fitting the EIS data of both samples associate the electrolyte resistance $(R e)$ in series with a $R_{t c} Q_{d l}-l o o p$, describing the outer charge transfer resistance in parallel to the double layer capacitance in the high frequencies. In the low frequency domain, the electrochemical behavior of anodized samples in $\mathrm{Na}_{2} \mathrm{SO}_{4}$ is different compared to those anodized in $\mathrm{CH}_{3} \mathrm{COOH}$. Indeed, the sodium sulfate bath involves a second loop consisting of a faradaic resistance $\left(\mathrm{R}_{\mathrm{f}}\right)$ and Warburg impedance (W) in parallel with a constant phase element associated to the inner-pores capacity (CPEp). However, the interface of the samples anodize in the acetic acid medium, the Warburg impedance is substituted by a constant phase element (CPEd) to describe the diffusion process. The CPE impedance, which expresses the inhomogeneity, porosity and the surface-roughness, is given by:

$Z_{\mathrm{CPE}}=\left[Q(j \omega)^{n}\right]^{-1}$

Where $Q\left(\mathrm{~F} \mathrm{~s}^{n-1}\right)$ and $n(-1 \leq n \leq 1)$ are frequency-independent constants, and $\omega$ the angular frequency.

Table 1 Polarization resistance of the anodized titanium samples

\begin{tabular}{|c|c|c|c|c|c|c|}
\hline & \multicolumn{6}{|c|}{ Anodizing time (minutes) } \\
\hline \multirow{3}{*}{$\operatorname{Rp}\left(10^{3} \times \mathrm{k} \Omega \mathrm{cm}^{2}\right)$} & \multicolumn{5}{|c|}{$\mathrm{Na}_{2} \mathrm{SO}_{4}$} & \multicolumn{3}{c|}{$\mathrm{CH}_{3} \mathrm{COOH}$} \\
\cline { 2 - 7 } & 15 & 30 & 45 & 15 & 30 & 45 \\
\cline { 2 - 7 } & 50,4 & 137 & 237 & 9,17 & 1,65 & 2,48 \\
\hline
\end{tabular}

The Table 1 summarizes all the polarization résistance values, for anodizing time of 15, 30 and 45 minutes, obtained by summing the values of the real resistances. It clearly establishes that the polarization resistance 
decreases when the anodizing time is extended in time. Indeed, the extension of the anodizing process enables to have pores of larger diameters, thereby increasing the accessibility of the electrolyte through the pores.

\section{CONCLUSION}

In this study, nano-structured titanium oxide layers were produced by the anodization technique at a bias potential of $20 \mathrm{~V}$, in both sodium sulfate bath and acetic acid medium, in the presence of fluoride ions (F-). The SEM characterization shows a well ordered TiO2-NT in $\mathrm{Na}_{2} \mathrm{SO}_{4}$ in contrast to $\mathrm{CH}_{3} \mathrm{COOH}$ medium. The DRX analysis reveals no significant influence of the nature of the electrolyte on the elementary composition of the elaborated phases. The diameter of the nanotubes $(\sim 80 \mathrm{~nm}$ in acetic acid medium) depends on the anodizing time. Biocompatibility has been studied in a physiological solution "HANK" by electrochemical impedance spectroscopy. The evolution of resistance Rp is confirmed with the result obtained by SEM observation. The increase in the anodizing duration leads to the formation of nanotubes having pores with larger diameters and more accessible to the electrolyte medium ions, which is translated by a decrease in polarization resistance.

\section{REFERENCES}

[1] G.A. CRAWFORD, N. CHAWLA, A. Bandyopadhyay" Microstructure and deforamtion befavior of biocompatible TiO2 nanotubes on titunium substrate" Acta Biomaterrialia, 3 (2007) .

[2] MIAO Z, XU D, OUYANG J, ZHAO X, et al "Electrochemically Induced Sol-cell Preparation of Single - Crystalline TiO2 Nanowires (2002).

[3] LI G., Z. LIU, Z. ZHANG and X. Y AN, "Preparation of Titania Nanotube Arrays by the Hydrithermal Method, Chin. J. Catal. 30: 37. ( 2009).

[4] TAI CC, TENG H, " Regulation of the Physical Caractéristic of Titania Nanotube Aggreggates Synthesized from Hydrothermal Treatment" Chem Mater (2004).

[5] CHEN Y, LU HH, WANG X, LU SS, "Large -Scal TiO2 nanotune arrays by anodization ", J. Mater Chem (2012).

[6] WU-QIANG WU, BING-XIN LEI, " Hydrothermal Fabrication of Hierarchically Anatase TiO2 Nnaowire arrays on FTO Class for Dye- senitizec Solar Cells", Scientific Repports 3, Article 1352.

[7] WANG J, LIN Z, " Anodic Formation of Oedered TiO2 Nnaotube Arrays: Effect of Electrolyte Temperature and anodization Potentiel” J. Physic Chem (2009).

[8] D. REGONINIA, A. SATKA, A. JAROENWORALUCK, D.W.E. Allsopp, C.R. Bowen, R. Stevens, Factors influencing surface morphology of anodized TiO2 nanotubes, Electrochimica Acta 74 (2012) 244- 253.

[9] XIANWU ZENG, YONG X. GAN, EVAN CLARK, LUSHENG SU,"Amphiphilic and photocatalytic behaviors of TiO2 nanotube arrays on Ti prepared via electrochemical oxidation", Journal of Alloys and Compounds, 509 (2011) L221-227.

[10] VARDAN G ALSTYAN, ELISABETTA COMINI, GUIDO FAGLIA and GIORGIO SBERVEGLIERI, "TiO2 Nanotubes: Recent advances in Synthesis and Gas Sensing Properties ", Sensors 2013" 14813-14838.

[11] L. MOHAN, C. ANANDAN, N. RAJENDRAN, "Electrochemical behaviour and bioactivity of self-organized TiO2 nanotube arrays on Ti-6Al-4V in Hanks' solution for biomedical applications”, Electrochimica Acta 155 (2015) 411-420.

[12] T. SHIBATA and Y-C. ZHU: 'The effect of film formation conditions on the structure and composition of anodic oxide films on titanium', Corros. Sci., 1995, 37, 253-270.

[13] J. L. ROSA, A. ROBIN, R. Z. NAKAZATO, M. B. RIBEIRO, M. P. PIASSA and M. B. SILVA, Formation of titania nanotube arrays by anodization: DOE approach, Surface Engineering 2014 DOI 10.1179/1743294413Y.0000000217

[14] Djamila ATMANI, Nadia SAOULA, ${ }^{*}$ Abderrezak ABDI, Mohamed AZZAZ, Youling WANG, and Mohamed MOHAMEDI. Structural, Morphological, and Electrochemical Corrosion Properties of TiO2 Formed on Ti6Al4V Alloys by Anodization, Cryst. Res. Technol. 2018, 1800138. 